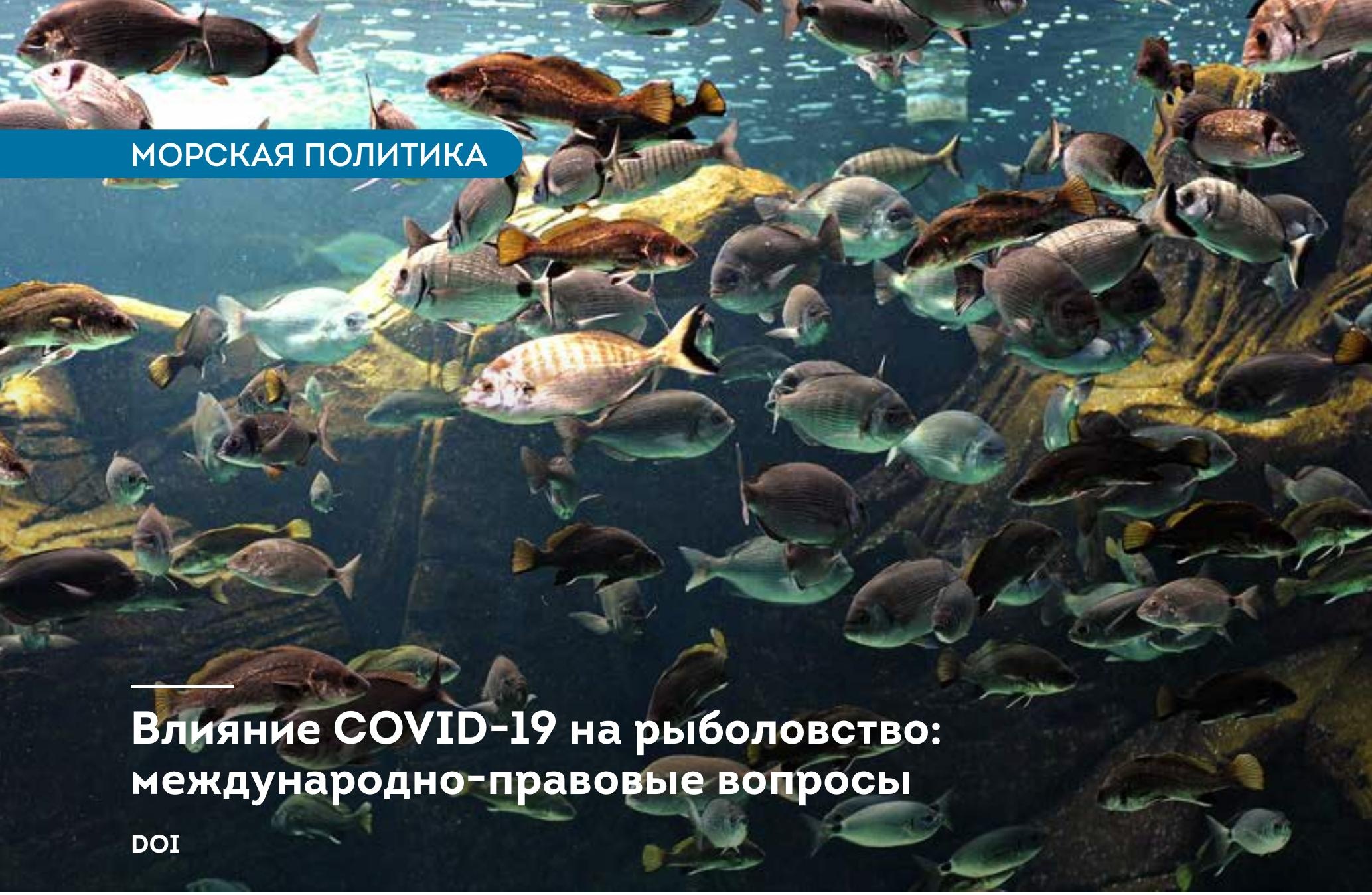

\section{Г.Г. Галстян - магистр} международного права, специалист Отдела международного рыболовного права, Всероссийский научноисследовательский институт рыбного хозяйства

и океанографии

(ФГБНУ «ВНИРО»)

\section{@galstyan17961801@mail.ru}

Ключевые слова: пандемия COVID-19, международно-правовые акты, право на здоровье моряков и рыбаков, мировое рыболовство

Keywords: COVID-19 pandemic, international legal acts, the right to health of seafarers and fishermen, world fisheries

\title{
IMPACT OF COVID-19 ON FISHERIES: INTERNATIONAL LEGAL ISSUES
}

G.G. Galstian - Master of international law, Specialist of International Fisheries Law Department, Russian Research Institute of Fisheries and Oceanography (FSBSI «VNIRO»),

galstyan17961801@mail.ru

The article deals with international legal issues related to the impact of the COVID-19 pandemic on the fishing industry. Legal and organizational measures taken at the global, regional and national levels to reduce the negative impact of coronavirus are analyzed in detail. The text describes the key international legal acts applicable to the issue under consideration.

На сегодняшний день рыболовная отрасль является источником доходов для десятков миллионов людей по всему миру, а также выступает в качестве одного из крупнейших поставщиков продуктов питания - жизненно важных для здоровья человека. Пандемия коронавируса стала очень тяжелым ударом для всего морского рыболовства. Кризис отрасли, связанный с распространением COVID-19, повлиял на личную безопасность и здоровье рыбаков, их условия труда и способность прибыть на борт судна и покинуть его, что, безусловно, оказывает влияние на их возможность по добыче рыбы и морепродуктов. Пандемия поставила человечество перед новыми вызовами и трудностями в области международно-правового регулирования отрасли. Выявленные проблемы потребовали незамедлительной реакции и ответных мер на глобальном, региональном и национальном уровнях.

\section{1. ПРИМЕНИМЫЕ МЕЖДУНАРОДНО- ПРАВОВЫЕ АКТЫ}

В результате развития пандемии перед международным сообществом встал вопрос: каковы инструменты международно-правового регулирования права на здоровье моряков и рыбаков. В этой связи необходимо обратиться к положениям ключевых между- 
народно-правовых актов, применимых к рассматриваемому вопросу.

Своеобразным «фундаментом» международного морского права, в том числе в области рыболовства, безусловно, является Конвенция ООН по морскому праву 1982 года. Однако данный документ в статье 98 содержит лишь общее положение об обязанности капитана судна оказывать помощь в случае бедствия на море. Международная конвенция по охране человеческой жизни на море 1974 г. и Международная конвенция по поиску и спасанию на море 1979 г. устанавливают обязательства государств принимать необходимые меры для оказания помощи лицам, терпящим бедствие на море. В статье 10 Международной конвенции о спасании 1989 г. содержится обязанность капитанов, не подвергая серьезной опасности свое судно и находящихся на нем лиц, оказывать помощь любому лицу, которому угрожает гибель в море. Вышеупомянутые нормы относятся и к вопросам охраны здоровья моряков и рыбаков.

В 2005 г. под эгидой Всемирной организации здравоохранения (ВО3) были приняты Международные медико-санитарные правила (ММСП). Они распространяют свое действие и на морское судоходство. Более того, в Конвенции по облегчению международного морского судоходства 1965 г. предусмотрено, что государства, не являющиеся участниками ММСП (2005 г.), должны стремиться применять те положения этих Правил, которые относятся к международному судоходству. Также в Конвенции установлен принцип, согласно которому не должно быть необоснованных ограничений или задержек для захода в порт судов, людей или имущества на борту и что, в случае чрезвычайной ситуации, судам может быть разрешено причаливать для эвакуации больных лиц.

Международно-правовым регулированием труда и охраны здоровья моряков и рыбаков занимается Международная организация труда (МOT). Конвенция МОТ о труде в рыболовном секторе 2007 г. в статье 38 предусматривает защиту в случае заболевания рыбаков при исполнении ими своих профессиональных обязанностей. Каждое государство-член принимает меры, обеспечивающие рыбаков защитой на случай заболевания, травмы или смерти, при исполнении ими своих профессиональных обязанностей, которые определяются в соответствии с национальным законодательством, нормативными правовыми актами или практикой [1].

\section{2. МЕРЫ, ПРЕДПРИНЯТЫЕ}

НА ГЛОБАЛЬНОМ УРОВНЕ

В условиях пандемии, ВОЗ также утвердила рекомендации в области общественного здравоохранения, которые также затрагивают право на охрану здоровья моряков. Данные рекомендации были разработаны на основа-
В статье рассмотрены международно-правовые вопросы, которые касаются влияния пандемии COVID-19 на рыболовную отрасль. Подробно проанализированы правовые и организационные меры по уменьшению негативного воздействия коронавируса, предпринятые на глобальном, региональном и национальном уровнях. В тексте описаны ключевые международно-правовые акты, применимые к рассматриваемому вопросу.

нии Конвенции МОТ о труде в морском судоходстве 2006 года. Как отмечает ВОЗ, в случае принятия мер, направленных на контроль и снижение негативных последствий пандемии коронавируса, портовым органам здравоохранения необходимо учитывать права моряков, которые установлены в данной Конвенции, в том числе путем предоставления морякам доступа к медицинской помощи на берегу и, в более общем плане, обеспечения защиты в вопросах безопасности и здоровья, включая доступ к службам охраны психического здоровья.

Ведущую роль в международной политике в области рыболовства играет Продовольственная и сельскохозяйственная организация ООН (ФАО), которая также оперативно отреагировала на сложившуюся ситуацию. В рамках ФАО были выработаны рекомендации по поддержанию сектора рыболовства и региональных рыбохозяйственных организаций (РФМО). Среди них следует выделить:

1) необходимость сосредоточиться на продовольственном потоке между государствами и обеспечить продовольственную цепочку, чтобы смягчить воздействие пандемии на продовольственное снабжение рыбной продукцией во всем мире;

2) требование выработать рекомендации для РФМО для обеспечения проведения мероприятий в удаленном формате. Вместе с тем представители ФАО отмечают, что использование электронных ресурсов может представлять серьезную угрозу для дипломатических обменов, в связи с возможными нарушениями конфиденциальности;

3) рассмотрение вопроса о разработке планов восстановления приоритетных областей, которые имеют тесную связь со сферой рыболовства и в которых негативное воздействие COVID-19 также высоко в отношении обеспечения продовольственной безопасности и возвращения к процессам устойчивого управления. Предварительное планирование восстановления пострадавших отраслей будет иметь ключевое значение для устранения задержек в осуществлении новых проектов и организации программ восстановления, а также активизации работы, как только это позволит ситуация, для решения или повторного решения управленческих проблем и пробелов [2]. 
Борьбу с последствиями пандемии осуществляет и Международная морская организация (ИМО). Она осуществляет обмен информацией о динамике развития пандемии между государствами-членами. Основными инструментами информирования государств-членов являются циркуляры ИМО, в которых прописаны рекомендации для государств, моряков и представителей судоходной отрасли, а также указания по внедрению и применению соответствующих актов ИМО, рекомендации по сертификации моряков и персонала рыболовных судов, а также рекомендации на случай непредвиденных задержек с подачей судов.

В апреле 2020 г. Совет ИМО призвал:

a) государства флага и государства порта обеспечить бесперебойное морское судоходство и доступность судоходных услуг для мировой торговли на благо человечества;

б) государства флага и государства порта обеспечить благополучие моряков, в частности - сохранить их право на заработную плату, увольнение на берег, отпуск по болезни, доступную медицинскую помощь, снабжение продовольствием и репатриацию;

в) правительства обмениваться передовым опытом защиты работников морского транспорта от заражения COVID-19, учитывая при этом национальные обстоятельства [3].

Еще одной международной площадкой для обсуждения политики в области рыболовства является Комитет по рыболовству Организации экономического сотрудничества и развития (КОФИ ОЭСР). В ноябре 2020 г. в режиме видеоконференцсвязи состоялось заседание 126-ой сессии КОФИ ОЭСР. В рамках проведения данного мероприятия представители ведущих рыболовных держав обсудили актуальные публикации ОЭСР, посвященные вопросам влияния коронавирусной инфекции на мировое рыболовство. Также делегаты представили доклады, в которых содержалась информация о положении национальной рыбной промышленности в связи с распространением пандемии. По итогам встречи было принято решение о необходимости публикации в ближайшее время 2 новых обзоров Организации, которые будут содержать наиболее актуализированную информацию о состоянии мировой рыбной промышленности и мерах государственной поддержки в условиях пандемии: «Обзор рыболовства-2020» и «COVID-19 и многостороннее управление рыболовством».

\section{3. МЕРЫ, ПРЕДПРИНЯТЫЕ}

\section{НА РЕГИОНАЛЬНОМ УРОВНЕ}

Ключевыми «игроками» в региональной политике в области рыболовства выступают РФМО.

Многие региональные организации уже отметили, что воздействие COVID-19 на их деятельность имеет серьезные негативные последствия. Среди них следует особо выделить следующие:

1. Из-за отмены или приостановления деятельности наблюдателей РФМО на судах воз- росло число случаев ННН рыбного промысла;

2. Серьезную озабоченность вызывает отсутствие независимого мониторинга, как процесса перегрузки рыбы и рыбной продукции в открытом море, так и перегрузки в исключительной экономической зоне (ИЭЗ), которые ранее осуществлялись в порту;

3. Расширение районов промысла кустарного рыболовства в прибрежных районах приводит к росту браконьерства в морских охраняемых районах (МОР). Именно поэтому отмечается важность наличия мониторинга, контроля и надзора, который будет иметь решающее значение для обеспечения того, чтобы прибрежные морские ресурсы не были чрезмерно эксплуатированы.

Следует отметить, что РФМО играют важную роль в содействии осуществления мониторинга, контроля и надзора за ведением рыболовства и борьбе с ННН рыбным промыслом. Успех их деятельности достигается за счет наличия во многих организациях комитетов по мониторингу и наблюдению, функциями которого являются мониторинг, обзор и оценка осуществления и соблюдения принятых мер по сохранению и управлению. Кроме того, комитеты по соблюдению, созданные в рамках многих РФМО, выносят рекомендации директивному органу о разработке новых мер по борьбе с несоблюдением. Отсутствие или сокращение объемов мониторинга и обеспечения соблюдения общих запасов в период пандемии может побудить государства, которые осуществляют промысел, вернуться к более

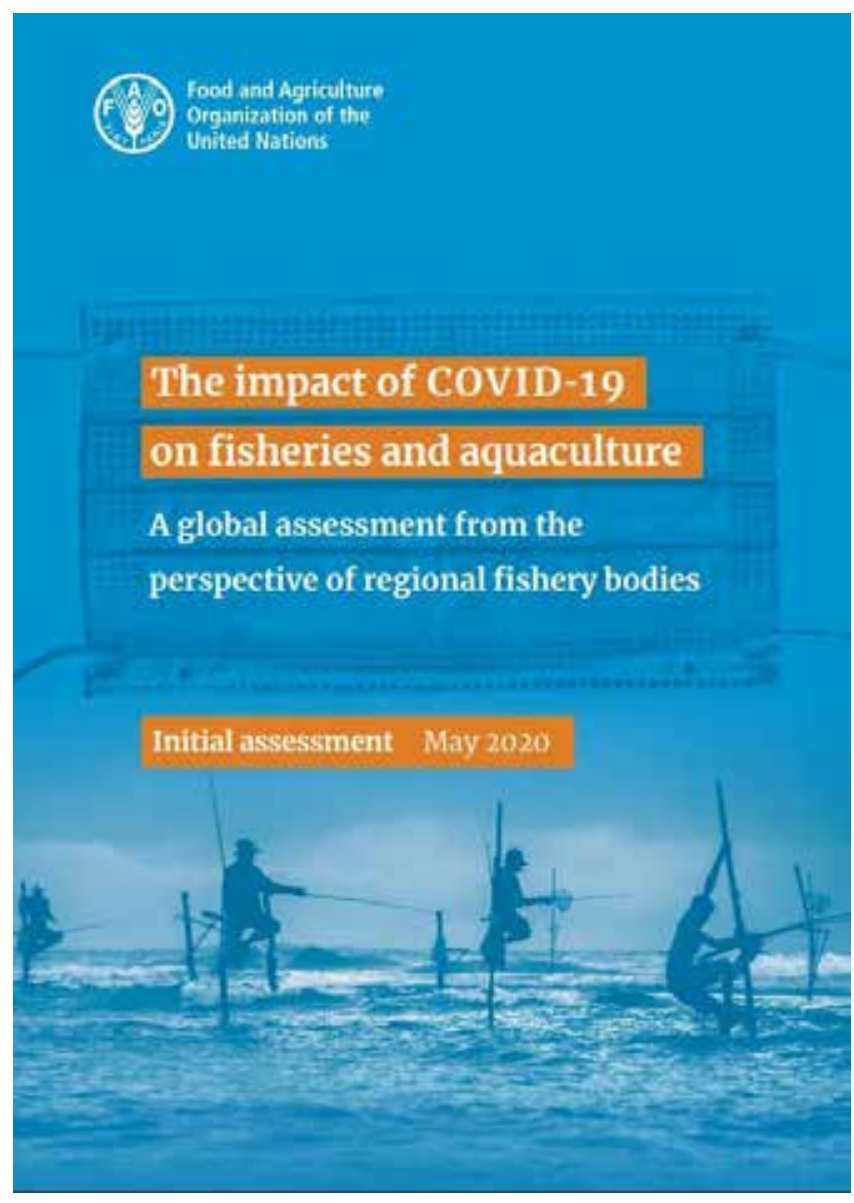


ответственному уровню управления, мониторинга и контроля над рыболовными операциями. Отмена или перенос на более поздние сроки заседаний вышеупомянутых комитетов может повлечь негативные последствия для рыболовной отрасли и борьбы с ННН рыбным промыслом. В этой связи представляется целесообразным предусмотреть организацию работы РФМО и их руководящих органов в сложившихся условиях.

Следует отметить, что роль РФМО заключается и в содействии проведения научных исследований в различных районах промысла. Это достигается, в первую очередь, за счет деятельности научных комитетов и специальных рабочих групп, которые создаются для работы над конкретными задачами. Именно благодаря функционированию подобных комитетов осуществляется руководство и рассмотрение всех оценок запасов различных видов рыб. Несмотря на то, что предпринимаются определенные усилия по проведению некоторых научных совещаний дистанционно, отмена и откладывание заседаний научных комитетов РФМО, а также совещаний иных международных организаций, которые занимаются вопросами оценки запасов и научных исследований, будут иметь среднесрочные и долгосрочные негативные последствия для рыбохозяйственной науки во всем мире. В настоящий момент многие РФМО стремятся решить данную проблему для того, чтобы позволить не нарушать привычный ход проведения научно-управленческих совещаний органов таких организаций.

Несмотря на многие сложности, с которыми сталкиваются РФМО в этом году, существуют и позитивные примеры организации работы многих региональных структур. Одним из самых богатых рыболовных районов в мире является Северо-Восточная Атлантика. В пределах данного региона активную деятельность осуществляет Комиссия по рыболовству в Северо-Восточной Атлантике (НЕАФК). В одном из своих заявлений НЕАФК отметила, что располагает эффективной и действенной системой мониторинга и контроля за рыболовством в своей зоне ответственности. Такая система, в сочетании с мерами контроля со стороны государства порта НЕАФК, обеспечила отсутствие незаконного, несообщаемого и нерегулируемого рыболовства в течение последних десяти лет. Эти меры контроля продолжают реализовываться во время событий COVID-19 в основном также, как и раньше [4].

Наиболее серьезным ударом пандемия стала для стран Европейского союза (ЕС). В рыболовной отрасли социальные партнёры в странах ЕС обратились с призывом к Европейской комиссии принять особые меры регулирования и обеспечить свободное передвижение рыбаков. Также было обращено внимание на конкретные проблемы, связанные с охраной здоровья рыбаков, максимальными периодами работы и квалификационными свидетельствами.

\section{4. МЕРЫ, ПРЕДПРИНЯТЫЕ} НА НАЦИОНАЛЬНОМ УРОВНЕ

Российская Федерация, как государствочлен многих международных организаций и РФМО, стремится следовать всем международно-правовым обязательствам, которые страна взяла на себя, как одна из ведущих рыболовных держав.

Законодательство Российской Федерации содержит нормы о регулировании вопросов жизни и здоровья граждан в сфере морского судоходства и рыболовства. Глава 3 ФЗ «О морских портах РФ» 2007 г. включает положения о государственном регулировании деятельности в морском порту. В данном Законе отмечено, что государственный портовый контроль осуществляется в том числе в целях обеспечения безопасности мореплавания, жизни и здоровья граждан.

Кроме того, следует отметить, что законодательство России не допускает к осуществлению профессиональных обязанностей на море лиц, чье состояние здоровья не соответствует предъявляемым требованиям. Так, например, морской лоцман не вправе осуществлять лоцманскую проводку судов, в случае несоответствия здоровья морского лоцмана предъявляемым к нему медицинским требованиям [5].

Принимая участие в международной онлайн-конференции «Мировой рыбный рынок: международное сотрудничество против пандемии», глава Росрыболовства Илья Шестаков отметил: «Росрыболовство немедленно отреагировало на объявление пандемии. В ведомстве создан оперативный штаб по контролю распространения COVID, обеспечено взаимодействие со смежными ведомствами: Роспотребнадзором, Росморречфлотом, Пограничной службой ФСБ России. Были введены жесткие меры контроля за состоянием здоровья судовых экипажей, в частности: обсервация перед рейсом, непрерывный мониторинг, запрет сходов на берег и ограничение контактов с береговым персоналом. Принятые меры в максимальной степени способствовали тому, что даже в самые пиковые периоды российская рыболовная отрасль работала без сбоев» [6].

Необходимость принятия дополнительных мер защиты граждан, занятых в области рыболовства, была очевидна и в других странах. Причем действия властей были направлены как на защиту права на здоровье моряков и рыбаков, так и на защиту продовольственной сферы. Например, морское управление Норвегии, с согласия организаций судовладельцев и моряков, подготовило руководство по вопросам смены экипажа и перевозки товаров и лекарств, включая процедуры найма и увольнения на берег и необходимую доку- 
ментацию моряков и рыбаков, касающуюся их квалификации, подготовки и состояния здоровья.

Активную политику по защите рыболовной отрасли от последствий пандемии проводит и КНР. Особые меры были направлены на запрет импорта замороженных продуктов питания из тех стран, которые серьезно пострадали от пандемии. Такие действия объясняются тем, что существуют серьезные опасения по поводу возможности передачи коронавируса через контакт с упаковкой продукции. Наглядным примером стала приостановка в октябре 2020 г. импорта морепродуктов с двух российских судов в результате обнаружения вируса на упаковке и образцах продукции. Кроме того, Китай запретил импорт с заводов Эквадора, Бразилии и Индонезии.

В августе 2020 г. главный вирусолог Китая предупредил, что правительство должно предотвратить проникновение коронавируса в страну через импортируемые замороженные продукты. Однако Управление по санитарному надзору за качеством пищевых продуктов и медикаментов США заявило, что ему «не известны какие-либо доказательства» того, что респираторный вирус может передаваться через пищевую продукцию [7].

\section{ВЫВОДЫ И ПРЕДЛОЖЕНИЯ}

Коронавирус стал серьезным испытанием для мирового рыболовства. Вместе с тем, рыба - важнейший источник полезных веществ для населения стран с низким уровнем дохода и дефицитом продовольствия и малых островных развивающихся государств, в которых рыбная продукция составляет основу рациона питания.

Наряду с этим, многие производители рыбной продукции несут большие убытки, а компенсации за потерю производства не достаточны, так как рыба, в процессе своей жизни, продолжает расти и требует кормления, в то время как продажи иссякают. Поэтому меры управления и политика государств и международных организаций должны учитывать потери доходов производителей вместе с потерями от производства. Следует полагать, что международному сообществу под эгидой ФАО необходимо подготовить планы действий в чрезвычайных ситуациях на случай гибели рыб в результате нехватки кормов или внешних факторов (например, засухи или болезней).

В этой связи усилия международного сообщества, а также национальные меры государств, принятые в соответствии с международно-правовыми актами и решениями международных организаций, играют первостепенную роль.

Представляется, что серьезным краеугольным камнем проблемы негативного влияния пандемии на рыболовство является и несовершенство обеспечения права на здоровье моряков и рыбаков, а также невозможность в полной мере осуществлять в этот кризисный период полный контроль за незаконными действиями судов, которые увеличивают количество случаев ННН рыбного промысла.

Следует полагать, что необходимо найти баланс между сохранением всего мирового рыболовства и охраной права на здоровье лиц, чья профессия связана с данной сферой. Весьма вероятно, что в дальнейшем мировому сообществу потребуется более детально урегулировать данную проблему. «Ключом» для ее решения является международное право.

\section{ЛИТЕРАТУРА И ИСТОЧНИКИ}

1. Бекяшев Д.К. Конвенция МОТ о труде в рыболовном секторе. Постатейный комментарий. М.: Изд-во ВНИРО, 2008. -188 c.

1. Bekyashev D. K. ILO Convention on labour in the fishing sector. Article-by-article commentary, Moscow: VNIRO Publishing house, 2008, $188 \mathrm{p}$.

2. The impact of COVID-19 on fisheries and aquaculture. A global assessment from the perspective of regional fishery bodies. FAO. 2020. 38 p.

2. The impact of COVID-19 on fisheries and aquaculture. A global assessment from the perspective of regional fishery bodies. FAO. 2020. 38 p.

3. Отраслевая справка МОТ. 17 апреля 2020 г. [Электронный pecypc] https://www.ilo.org/wcmsp5/groups/public/---ed_ dialogue/---sector/documents/briefingnote/wcms_749291.pdf [дата обращения: 15.11.2020 г.].

3. Industry the help of the ILO. April 17, 2020 [Electronic resource] https://www.ilo.org/wcmsp5/groups/public/ed_ dialogue/sector/documents/briefingnote/wcms_749291.pdf [accessed: 15.11.2020].

4. Submission by the North-East Atlantic Fisheries Commission regarding the report of the Secretary-General of the United Nations on Oceans and the Law of the Sea, pursuant to General Assembly resolution 74/19. [Электронный ресурc] https://www.un.org/ depts/los//general_assembly/contributions_2020/NEAFC.pdf [дата обращения: 17.11.2020].

4. Submission by the North-East Atlantic Fisheries Commission regarding the report of the Secretary-General of the United Nations on Oceans and the Law of the Sea, pursuant to General Assembly resolution 74/19. [Electronic resource] https://www. un.org/depts/los//general_assembly/contributions_2020/ NEAFC.pdf [accessed: 17.11.2020].

5. Бекяшев К.А. Морское рыболовное право: учебник. - 3-е изд., доп. и испр. - Москва: Проспект, 2021. - 640 с.

5. Bekyashev K. A. Sea fishing law: textbook. - 3rd ed., add. and ISPR. - Moscow: Prospect, 2021 - 640 p.

6. Илья Шестаков принял участие в международной онлайнконференции «Мировой рыбный рынок: международное сотрудничество против пандемии». Новости Росрыболовства от 22 сентября 2020 г. [Электронный ресурс] http://fish.gov.ru/ obiedinennaya-press-sluzhba/novosti/31420-ilya-shestakovprinyal-uchastie-v-mezhdunarodnoj-onlajn-konferentsiimirovoj-rybnyj-rynok-mezhdunarodnoe-sotrudnichestvo-protivpandemii [дата обращения: 18.11.2020].

6. Ilya Shestakov took part in the international online conference "World fish market: international cooperation against the pandemic". News of the Agency dated September 22, 2020 [Electronic resource] http://fish.gov.ru/obiedinennaya-presssluzhba/novosti/31420-ilya-shestakov-prinyal-uchastie-vmezhdunarodnoj-onlajn-konferentsii-mirovoj-rybnyj-rynokmezhdunarodnoe-sotrudnichestvo-protiv-pandemii [accessed: 18.11.2020].

7. Информационный бюллетень Международного рыбного обозрения (МРО). № 24 (91). Октябрь 2020. - 22 с.

7. Newsletter of the International fish review (IRO). № 24 (91). October 2020 - 22 c. 